Article

\title{
Investigation of RNA Editing Sites within Bound Regions of RNA-Binding Proteins
}

\author{
Tyler Weirick ${ }^{1,2}$ (), Giuseppe Militello ${ }^{1,3}$, Mohammed Rabiul Hosen ${ }^{4}$, David John ${ }^{5}$, \\ Joseph B. Moore IV ${ }^{6,7}$ and Shizuka Uchida 1,6,7,*(D) \\ 1 Cardiovascular Innovation Institute, University of Louisville, Louisville, KY 40202, USA; \\ shizuka.uchida@louisville.edu \\ 2 RIKEN Center for Integrative Medical Sciences (IMS), 1-7-22 Suehiro-cho, Tsurumi-ku, Yokohama 230-0045, \\ Japan; tyler.weirick@gmail.com \\ 3 Department of Molecular Cellular and Developmental Biology, Yale University, Yale Science Building-260 \\ Whitney Avenue, New Haven, CT 06511, USA; giuseppe.militello@yale.edu \\ 4 Department of Internal Medicine-II, Molecular Cardiology, Biomedical Center (BMZ), University of Bonn, \\ Sigmund-Freud-Str. 25, Bonn 53127, Germany; hosenmr@uni-bonn.de \\ 5 Institute of Cardiovascular Regeneration, Centre for Molecular Medicine, Goethe University Frankfurt, \\ Theodor-Stern-Kai 7, Frankfurt am Main 60590, Germany; John@med.uni-frankfurt.de \\ 6 The Christina Lee Brown Envirome Institute, Department of Medicine, University of Louisville, Louisville, \\ KY 40202, USA; joseph.moore@louisville.edu \\ 7 Diabetes and Obesity Center, University of Louisville, Louisville, KY 40202, USA \\ * Correspondence: heart.lncrna@gmail.com; Tel.: +1-502-854-0570
}

Received: 17 October 2019; Accepted: 27 November 2019; Published: 29 November 2019

\begin{abstract}
Studies in epitranscriptomics indicate that RNA is modified by a variety of enzymes. Among these RNA modifications, adenosine to inosine (A-to-I) RNA editing occurs frequently in the mammalian transcriptome. These RNA editing sites can be detected directly from RNA sequencing (RNA-seq) data by examining nucleotide changes from adenosine (A) to guanine $(\mathrm{G})$, which substitutes for inosine (I). However, a careful investigation of such nucleotide changes must be conducted to distinguish sequencing errors and genomic mutations from the genuine editing sites. Building upon our recent introduction of an easy-to-use bioinformatics tool, RNA Editor, to detect RNA editing events from RNA-seq data, we examined the extent by which RNA editing events affect the binding of RNA-binding proteins (RBP). Through employing bioinformatic techniques, we uncovered that RNA editing sites occur frequently in RBP-bound regions. Moreover, the presence of RNA editing sites are more frequent when RNA editing islands were examined, which are regions in which RNA editing sites are present in clusters. When the binding of one RBP, human antigen R [HuR; encoded by ELAV-like protein 1 (ELAV1)], was quantified experimentally, its binding was reduced upon silencing of the RNA editing enzyme adenosine deaminases acting on RNA (ADAR) compared to the control-suggesting that the presence of RNA editing islands influence HuR binding to its target regions. These data indicate RNA editing as an important mediator of RBP-RNA interactions-a mechanism which likely constitutes an additional mode of post-transcription gene regulation in biological systems.
\end{abstract}

Keywords: RNA; RNA editing; RNA-seq; RNA-binding proteins; transcriptome

\section{Introduction}

The life of RNA is more complex than previously thought. Upon transcription from DNA, RNA is modified by a variety of enzymes, resulting in over 140 types of RNA modifications [1]. These modifications are increasingly implicated in various pathophysiological conditions, findings that 
have emboldened the field of epitranscritomics [2-4] to rapidly expand and focus efforts on delineating the role of RNA modifications in disease etiology [5]. Among various RNA modifications, RNA editing is particularly interesting, as it can be detected directly from RNA sequencing (RNA-seq) data [6]. RNA editing is a post-transcriptional modification that alters the sequence of RNA molecules $[7,8]$. Differing from 5'-capping, 3'-polyadenylation, and splicing, RNA editing modifies RNA molecules by the insertion, deletion, or base substitution of nucleotides via RNA editing enzymes to diversify the resulting transcripts. When RNA editing takes place in exons of protein-coding genes, an amino acid sequence that is different from the original DNA sequence could arise, whereas editing of 3'-untranslated regions (UTRs) may affect binding of RNA binding proteins or microRNAs (miRNAs) to modulate RNA stability and/or translation [7].

There are two types of RNA editing: adenosine to inosine (A-to-I) and cytidine to uridine (C-to-U), where A-to-I is the most common form. A-to-I editing occurs through RNA editing enzymes, adenosine deaminases acting on RNA (ADARs), which convert adenosine (A) in double-stranded RNA into inosine (I). Although A-to-I editing occurs at the RNA level, when reverse transcribed to complementary DNA (cDNA), an inosine is converted to guanine $(\mathrm{G})$. This A-to-G conversion, which is evidence for RNA editing sites, may be simply identified by comparing resultant cDNA sequences to the reference genome [9]. In mammals, there are three ADARs (ADAR1, ADAR2, and ADAR3). Although ADAR3 (also known as Adarb2-adenosine deaminase, RNA-specific, B2) is considered to be catalytically inactive and a less important player in RNA editing events [10], the knockout mice of Adar1 and Adar2 (also known as Adarb1-adenosine deaminase, RNA-specific, B1) are embryonically and postnatally lethal, respectively [11,12], which highlights the importance of RNA editing events in normal development. Given the importance of ADARs, a number of studies have conducted experiments to detect RNA editing events from RNA-seq data [13-18], including the one that we recently reported in endothelial cells [19]. The most challenging part of such identification is the separation of true RNA editing sites from genomic variations (e.g., single nucleotide polymorphisms (SNPs)), which are distinguished by a series of filters [20-27]. However, there is a lack of easy-to-use bioinformatics tools to analyze RNA editing events. To this end, we recently developed a new bioinformatics tool, RNAEditor [28], to assist the discovery of RNA editing events without extensive knowledge about programming.

Besides ADARs, there are many proteins that bind to RNAs. In terms of RNA binding, there is a protein domain called RNA recognition motif (RRM), which binds to single-stranded RNAs (https://www.ebi.ac.uk/interpro/entry/IPR000504). When a protein owns an RRM domain, it is generally categorized as an RNA-binding protein (RBP). Because many RBPs are pathophysiologically important [29-35], there is a growing interest in studying RBPs. These interests have stimulated the development of various experimental techniques, including several forms of RNA immunoprecipitation (RIP) followed by next generation sequencing (NGS) (called RIP-seq [36,37]). Such techniques include crosslinking-immunoprecipitation (CLIP) followed by NGS (CLIP-seq [38]; also known as high-throughput sequencing of RNA isolated by crosslinking immunoprecipitation (HITS-CLIP)), photoactivatable ribonucleoside-enhanced crosslinking and immunoprecipitation (PAR-CLIP) [39], and individual-nucleotide resolution UV cross-linking and immunoprecipitation (iCLIP) [40,41]. Essentially, all of these techniques are performed on a genome-wide scale to identify RNA target sequences that RBPs may bind to. To avoid confusion, in this study, all of these variations of RIP-seq are collectively called CLIP-seq. Furthermore, there are established databases to utilize the information obtained from individual laboratories to facilitate continued research efforts that seek to understand the consequence of binding of (or lack of) RBP. Such databases include CLIPdb [42], MitBase [43], POSTAR [44], and starBase [45,46]. These systematically collected and cataloged CLIP-seq data provide a stage for further bioinformatics analysis of RBPs and their interacting RNA consensus sequences.

Given that most RBPs recognize and bind in a sequence-specific manner (specific RNA-binding motifs), it is not unsurprising that mutations in such binding motifs (both in RBP and their bound RNA sequences) would alter RBP binding capacity. As A-to-I RNA editing occurs rather frequently in 
the transcriptome [28], it is not surprising that RNA editing alters the binding of RBP. These alterations include the changes in miRNA binding sites, which are loaded onto RNA-induced silencing complex (RISC) that include Argonaute (AGO) protein family as RBP [19,47-50]. Although bits and pieces of information are available, there is not a systematic investigation of RBP and their bound sequences that could be altered by RNA editing. Here, utilizing the available information and bioinformatics tools, we dissected how RNA editing sites alter the binding of RBP, which may have consequences on cellular physiology.

\section{Materials and Methods}

\subsection{Data Sources}

For CLIP-seq data, the analyzed data were downloaded from starBase [45,46]. For RNA editing sites, the analyzed data were downloaded from RADAR [27]. All of the above datasets were originally mapped to hg19. In order to avoid any biases resulting from further secondary data analysis, the data were downloaded from the above databases without any modifications. To identify the RNA editing sites within RBP-binding regions, the intersect command of BEDTools [51] with the "-wo" option was used.

To identify RNA editing sites and islands, the following RNA-seq data of HEK-293 cells were analyzed with RNAEditor [28]: SRR3994124, SRR3994125, SRR3994126, SRR629569, and SRR629570 (all are from the Sequence Read Archive (SRA)).

\subsection{Culturing of Cells, $q R T-P C R$, and siRNAs}

HEK-293 cells were cultured in growth medium consisting of Dulbecco's Modified Eagle Medium (DMEM) with low glucose and pyruvate (Thermo Fischer Scientific, Darmstadt, Germany) supplemented with 10\% fetal bovine serum (FBS) (Thermo Fischer Scientific, Darmstadt, Germany), and antibiotics (100 units of penicillin and $100 \mu \mathrm{g}$ of streptomycin per milliliter, Sigma-Aldrich, Hamburg, Germany). Cells were propagated under standard incubation conditions with $5 \%$ atmospheric $\mathrm{CO}_{2}$ at $37^{\circ} \mathrm{C}$, as previously described $[52,53]$.

Transient transfection of small interfering RNA (siRNA) duplexes against ADAR (Sigma-Aldrich, Hamburg, Germany\#SASI_Hs01_00244017) (10 nM) was carried out using RNAiMax (Thermo Fischer Scientific, Darmstadt, Germany) according to the manufacturer's protocol. The corresponding amount of control siRNA (MISSION Negative control SIC002, confidential sequence (Sigma-Aldrich, Hamburg, Germany) was used. Forty-eight hours after the transfection of siRNAs, cells were harvested using TRIzol (Thermo Fischer Scientific, Darmstadt, Germany) to extract RNA or lysed for protein analysis.

After the purification and treatment of total RNA with TURBO DNase (Thermo Fischer Scientific, Darmstadt, Germany) to digest genomic DNA, $1 \mu \mathrm{g}$ of RNA was reverse transcribed with SuperScript VILO Master Mix (Thermo Fischer Scientific, Darmstadt, Germany). For quantitative reverse transcription polymerase chain reaction (qRT-PCR), $1 \mu \mathrm{L}$ of the cDNA template was used with Fast SYBR Green Master Mix (Thermo Fischer Scientific) via StepOne Plus Real-Time PCR System (Applied Biosystem, Darmstadt, Germany) with the following thermal cycling condition: $95^{\circ} \mathrm{C}$ for $20 \mathrm{sec}$ followed by 40 cycles of $95^{\circ} \mathrm{C}$ for $3 \mathrm{~s}$ and $60^{\circ} \mathrm{C}$ for $30 \mathrm{~s}$. Relative fold expression was calculated by $2^{-\Delta \Delta \mathrm{Ct}}$ using glyceraldehyde 3-phosphate dehydrogenase (GAPDH) as an internal control. The list of primer sequences can be found in Table S1.

\subsection{Western Blotting}

Western blotting experiments were carried out via Expedeon Blot System (Expedeon, Cambridge, United Kingdom) using pre-cast $4 \%-12 \%$ gradient SDS-PAGE gel (Expedeon, Cambridge, United Kingdom). For each well, $50 \mu \mathrm{g}$ of total extract were diluted in $20 \mu \mathrm{L}$ of RunBlue LDS Sample Buffer (Expedeon, Cambridge, United Kingdom) with $0.1 \mathrm{M}$ dithiothreitol (DTT) and loaded 
after boiling at $70{ }^{\circ} \mathrm{C}$ for $10 \mathrm{~min}$. The samples were fractionated by migration under 180 volts for 70-90 min.

After the electrophoretic separation, gels were blotted in TGS Buffer 1X (0.025 M Tris, $0.192 \mathrm{M}$ glycine, $10 \%$ methanol, and $0.1 \%$ SDS) using polyvinylidene fluoride (PVDF) membrane (Amersham, Munich, Germany) with a constant voltage of 200 volts at $4{ }^{\circ} \mathrm{C}$ for $90 \mathrm{~min}$. After the transfer, the membrane was blocked with 5\% skimmed milk diluted in tris-buffered saline (TBS) for $60 \mathrm{~min}$. Then, the membrane was incubated with the following antibodies (diluted in 5\% skimmed milk TBS) at $4{ }^{\circ} \mathrm{C}$ for overnight: anti-ADAR1 (Abcam, Cambridge, United Kingdom, \#ab88574; diluted at 1:500) and anti-histone H3 (Abcam, \#1791; diluted at 1:1000) as a loading control. After primary antibody incubation, the membrane was extensively washed with $5 \%$ skimmed milk diluted in TBS with $0.5 \%$ of Tween 20 (TBS-T) and incubated with anti-rabbit-HRP (horseradish peroxidase; Roth; diluted at 1:1000) in 5\% skimmed milk + TBS-T. After three 15 min washes with 5\% milk and TBS-T, the membrane was revealed using Luminata Forte Western HRP substrate (Merck Millipore, Darmstadt, Germany) via C-DiGit Blot Scanner (LI-COR).

\subsection{RNA Immunoprecipitation (RIP)}

Magna RIP Kit (Millipore, Darmstadt, Germany) was used according to the manufacturer's protocol. For each RIP reaction, $100 \mu \mathrm{L}$ of cellular pellet from HEK-293 cells was fixed with $1 \%$ formaldehyde in PBS at room temperature for $10 \mathrm{~min}$. Cross-linking reaction was stopped by adding $590 \mu \mathrm{L}$ of $2.5 \mathrm{M}$ glycine. Fixed cells were subsequently harvested and resuspended in RIP lysis buffer supplemented with protease/RNAse inhibitors. Lysate was obtained using a dounce homogenizer on ice (dounced 10 times for releasing nuclei) followed by incubation on ice for $15 \mathrm{~min}$. An equal volume of RIP lysis buffer was added to the cellular pellet. From the solution, $10 \mu \mathrm{L}(10 \%)$ of lysate was removed and stored as an "input". For each RIP reaction, $100 \mu \mathrm{L}$ of lysate was mixed with $5 \mu \mathrm{g}$ of rabbit anti-IgG (immunoglobulin G; negative control provided with the kit), anti-HuR (Millipore, \#03-102), and anti-AGO2 (Argonaute 2; Millipore, \#03-110) antibodies previously conjugated with protein A/G magnetic beads (provided with the kit). After incubation at $+4{ }^{\circ} \mathrm{C}$ overnight, RNA-protein immune complex was extensively washed with RIP Wash Buffer (provided with the kit). The cross-linking was reversed by incubation with proteinase $\mathrm{K}$. The immune-precipitated RNA was purified through phenol/chloroform/isoamyl alcohol (5:1:1). The purified immuno-precipitated RNA was treated with DNase I and reverse transcribed using SuperScript VILO Master Mix.

\section{5. $R N A-s e q$}

One microgram of DNase-I-treated total RNA was used for the strand-specific cDNA library construction at Novogene (Sacramento, CA, USA) using NEBNext Ultra Directional RNA Library Prep Kit for Illumina (New England BioLabs, \#E7420L) according to the manufacturer's protocol. Briefly, ribosomal RNA was removed using Ribo-Zero rRNA Removal kit (Illumina, San Diego, CA, USA, \#MRZH11124), and fragmented randomly by adding fragmentation buffer. The first strand cDNA was synthesized using random hexamer primers. The second strand cDNA was generated incorporating deoxyuridine triphosphate (dUTP) in place of deoxythymidine triphosphate (dTTP) to create blunt-ended cDNA. After a series of terminal repair, poly-adenylation, and sequencing adaptor ligation, the double-stranded cDNA library was completed following size selection and PCR enrichment. The resulting 250-350 bp insert libraries were quantified using a Qubit 2.0 fluorometer (Thermo Fisher Scientific) and quantitative PCR. The size distribution was analyzed using an Agilent 2100 Bioanalyzer. Qualified libraries were sequenced on an Illumina HiSeq 4000 Platform using a paired-end 150 run $(2 \times 150$ bases $)$. A minimum of 40 million raw reads were generated from each library.

The RNA-seq data generated in this study were deposited in the Gene Expression Omnibus (GSE141095). 


\subsection{Statistics}

Data are presented as mean \pm standard error of the mean (S.E.M.). F-test was applied for normality. Two-sample, two-tailed Student's $t$-test was performed to calculate a $p$-value via Microsoft Excel.

\section{Results}

\subsection{Presence of RNA Editing Sites in RBP-Bound Regions}

Given that CLIP-seq utilizes NGS as readout, in principle, it is possible to identify the presence of RNA editing sites within the sequences that RBPs bind. To test this possibility, the analyzed CLIP-seq data were downloaded from the starBase database $[45,46]$. Among all CLIP-seq data available in the starBase database, human embryonic kidney cells 293 (HEK-293) were chosen for further analysis because they constitute the largest number of analyzed data (48 out of 86 available datasets). In CLIP-seq data of HEK-293 cells, 27 RBP were targeted. Using the RBP-bound regions identified from CLIP-seq data (Table S2), the presence of RNA editing sites was searched via the RADAR database [27]. When these sites were examined for their genic locations, numerous RNA editing sites were identified in the RBP-bound regions (Figure 1; Table S3), although there were significant variations among the RBPs examined. These RNA editing sites can be found in both Alu (Table S4) and non-Alu elements (Table S5), as RBP recognize specific sequences. Given that $75.17 \%$ of the RNA editing sites in both Alu and non-Alu elements were found in the intronic regions followed by intergenic and 3'-UTR (20.06\% and $3.31 \%$, respectively) (Table 1), it was not surprising that many RBP-bound regions with RNA editing sites were found in these three regions.

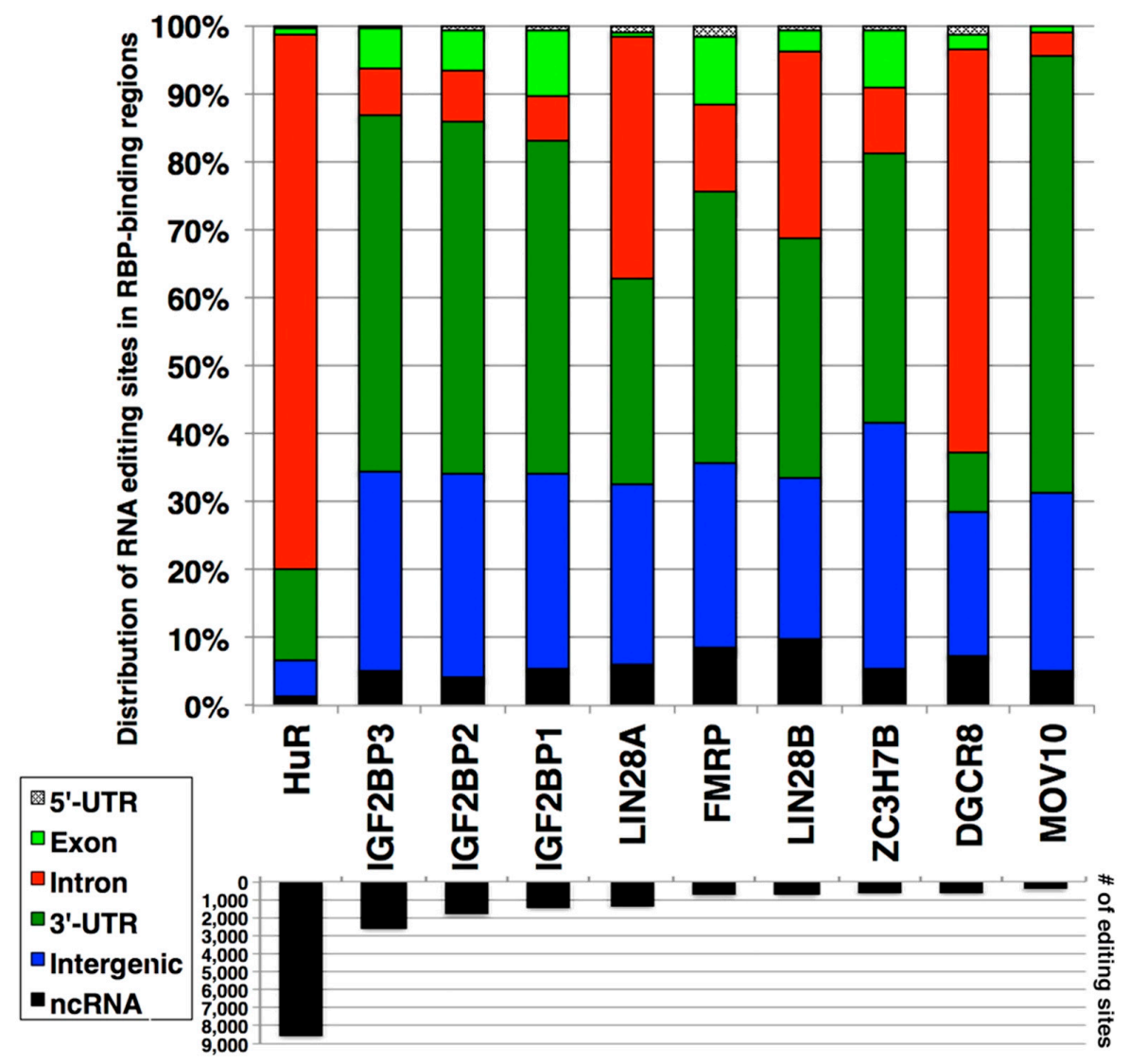

Figure 1. Overlap between RNA editing sites and RNA-binding protein (RBP)-bound regions. The upper graph shows the genic distribution of the overlapped sites. The lower graph indicates the number of overlapping RNA editing sites. The top 10 overlapping RBPs are shown. $5^{\prime}$-untranslated region (5'-UTR); 5'-untranslated region (3'-UTR); non-coding RNA (ncRNA). 
Table 1. Distribution of genic locations of RNA editing sites listed in the RADAR database.

\begin{tabular}{cccc}
\hline Genic Location & All Sites & Alu & Non-Alu \\
\hline $5^{\prime}$-UTR & 6775 & 6131 & 644 \\
Exon & 4405 & 2082 & 2323 \\
Intron & $1,936,801$ & $1,870,644$ & 66,157 \\
$3^{\prime}$-UTR & 85,169 & 79,434 & 5735 \\
Intergenic & 516,714 & 479,480 & 37,234 \\
ncRNA & 26,595 & 24,184 & 2411 \\
\hline
\end{tabular}

The merged data above show large numbers of RNA editing sites in RBP-bound regions, which raises the question as to whether such RNA editing sites are real. Given that the RADAR database contains RNA editing sites from various cell types and tissues, it could be that the above approach overestimated the number of RNA editing sites present in RBP-bound regions. Furthermore, these RNA editing sites are not strictly from HEK-293 cells, in which RBP-bound regions were identified. To investigate this point, the published RNA-seq data of HEK-293 cells were analyzed using our RNAEditor [28], which resulted in the identification of 109,283 RNA editing sites. Indeed, fewer numbers of RNA editing sites were identified in RBP-bound regions in HEK-293 cells (Table S6) compared to various cell types and tissues from the RADAR database (Table S3). On the basis of these results, we concluded that the same cell type must be used for the analysis of RNA editing sites and their presence in RBP-bound regions.

\subsection{Consequence of Loss of ADAR for the Binding of RBP}

ADARs catalyze RNA deamination on the basis of their structures rather than having the defined sequence motif [54-57]. This fact makes it difficult to simply compare the sequence motifs of RBP to those of ADARs to derive RBP-binding sites to be edited. As we previously reported [28], it is rather common that RNA editing sites are present in clusters, which we named RNA editing islands [28]. As these RNA editing islands reflect the bound regions of ADAR, which were verified by RIP-seq data generated using anti-ADAR antibody [58], RNA editing islands could be viewed as more probable and important RNA editing sites. Given the situations discussed above, we examined the degree of overlaps between RNA editing islands and RBP-bound regions in HEK-293 cells. From the RNA-seq data of HEK-293 cells, 21,120 RNA editing islands were identified using our RNAEditor (Table 2; Table S7). When these RNA editing islands were compared to the RBP-bound regions (Table S8), HuR-bound regions possessed the greatest number of RNA editing islands, which is consistent with previous reports regarding ADAR-regulating gene expression and stability of messenger RNAs (mRNAs) via interaction with $\mathrm{HuR}$, as in the case of cathepsin S (CTSS) [19].

Although the evidence above is informative, one cannot reliably conclude that RNA editing sites and islands have effects on RBP-bound regions. To investigate this point, we hypothesized that upon silencing of ADAR via siRNA, the number of RNA editing islands and the magnitude of RBP binding will be altered compared to the control condition (i.e., HEK-293 cells transfected with siRNA against random sequence) (Figure 2A). To test this hypothesis, we chose to knockdown ADAR (ADAR1), whose binding overlaps to RNA editing islands [28]. The siRNA against ADAR targets both isoforms of ADAR1, which are p110 and p150 (Figure 2B). For the RBP, HuR was chosen, as this RBP showed the greatest number of RNA editing sites and islands in its bound regions (Figure 1). RNA immunoprecipitation, followed by RT-PCR (RIP-PCR) experiment, was performed for six genes [CYP20A1 (cytochrome P450, family 20, subfamily A, polypeptide 1), GNL3L (G protein nucleolar 3 like), LYRM7 (LYR motif containing 7), MAVS (mitochondrial antiviral signaling protein), PDDC1 (Parkinson disease 7 domain containing 1), and TAF8 (TATA-box binding protein associated factor 8)] by using primer pairs targeting their 3'-UTR regions, which overlapped between the RNA editing islands and HuR-binding regions (Figure 2C). The result showed that significantly less binding of HuR to these genes was recorded for half of the genes (CYP20A1, GNL3L, and LYRM7), suggesting that, 
to a certain extent, the existence of RNA editing islands is necessary for the efficient binding of HuR. To investigate this finding further, RNA-seq experiment was performed upon silencing of ADAR in HEK-293 cells. When the RNA editing sites were compared for the six genes above, the decreased numbers of RNA editing sites were detected for CYP20A1, GNL3L, LYRM7, and MAVS, especially in 3'-UTR regions (Table S9). However, no RNA editing sites were detected in 3'-UTR regions of PDDC1 and TAF8, which suggest for no difference in binding of HuR, as shown in Figure 2C.
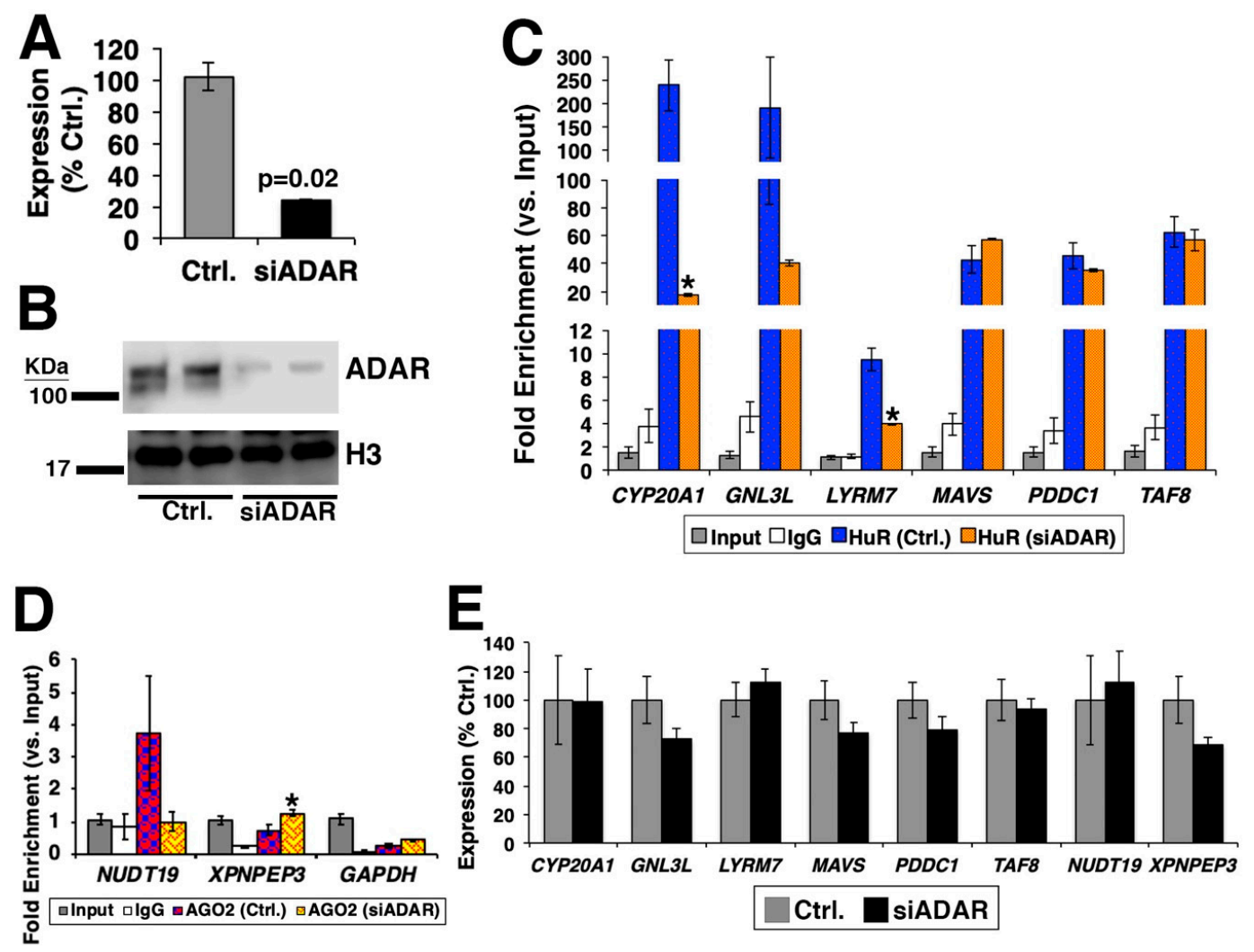

Figure 2. Knockdown of adenosine deaminases acting on RNA (ADAR) in HEK-293 cells. (A) qRT-PCR results of ADAR expression upon silencing of ADAR (siADAR). HEK-293 cells transfected with siRNA against random sequence was used as control (Ctrl.). $n=3$ technical replicates. (B) Western blotting results of normally grown HEK-293 cells (normal), control, and silencing of ADAR. Antibodies against ADAR and histone H3 (as a loading control) were used. $n=2$ technical replicates. (C,D) RNA immunoprecipitation (RIP)-PCR. $n=3$ technical replicates. The fold enrichment was calculated against the average $\mathrm{Ct}$ value of the input. ${ }^{*}$ represents $p<0.05$ comparing $(\mathbf{C}) \mathrm{HuR}$ - and (D) AGO2-binding between silencing of ADAR and control. (E) Expressions of genes. $n=3$ technical replicates. No statistically significant difference between silencing of ADAR and control was recorded in all genes.

To further confirm the above findings, another RBP was tested. Given that the previous data targeted 3'-UTR regions, we chose to test for the alteration in binding of Argonaute protein, which is an essential component of RNA-induced silencing complex (RISC). As shown in Figure 2D, silencing of $A D A R$ affected the binding of argonaute RISC catalytic component 2 (AGO2). As ADAR was knocked down, it could be possible that the expressions of these genes were reduced, which caused alterations in binding of RBPs to these genes. However, this was not the case, as all genes showed no statistically significant difference in their expressions between the control and silencing of $A D A R$ (Figure 2E). These data confirm that reduction of RNA editing islands caused by silencing of $A D A R$ affects the binding of RBPs. 
Table 2. Distribution of genic locations of RNA editing islands of HEK-293 cells.

\begin{tabular}{cc}
\hline Genic Location & Count \\
\hline $5^{\prime}$-UTR & 50 \\
$5^{\prime}$-UTR;Intron & 10 \\
Exon & 20 \\
Exon;Intron & 9 \\
Intron;Exon & 17 \\
Intron;5'-UTR & 4 \\
Intron & 16,707 \\
Intron;3'-UTR & 14 \\
Intron;ncRNA & 33 \\
3'-UTR & 590 \\
$3^{\prime}$-UTR;Intergenic & 2 \\
$3^{\prime}$-UTR;Intron & 4 \\
Intergenic;5'-UTR & 1 \\
Intergenic & 3376 \\
Intergenic;3'-UTR & 2 \\
Intergenic;ncRNA & 3 \\
ncRNA & 258 \\
ncRNA;Intron & 18 \\
ncRNA;Intergenic & 2 \\
\hline
\end{tabular}

\section{Discussion}

In this study, the extent to which RNA editing events affect RBP binding was investigated. Building upon our recently introduced RNAEditor bioinformatics tool to detect RNA editing sites and islands from RNA-seq data, we examined the overlap between RNA editing events and RBP-bound regions. Here, we experimentally validated the necessity of ADAR RNA editing enzyme to the binding of the RBP HuR in HEK-293 cells. The major findings of this study were (1) many RNA editing sites can be found in the regions that RBPs bind to; (2) RNA editing islands can be used to investigate the influence of RNA editing events to RBP-bound regions; and (3) experimentally, the lack of RNA editing islands upon silencing of RNA editing enzyme ADAR reduces HuR binding compared to the control.

Utilizing CLIP-seq data in HEK-293 cells, we examined 27 RBP and their binding to RNA editing sites. Among these RBPs, by far, HuR (encoded by ELAVL1 gene) bound the most often to RNA editing sites. Given that HuR stabilizes RNAs to regulate gene expression [59-61], it is tempting to speculate that RNA editing sites promote the binding of HuR to stabilize the edited transcripts, as we have shown in our previous study for cathepsin S (CTSS) in endothelial cells [19]. Although an earlier study indicated such a mechanism of action [58], two other studies that investigated this interaction between RNA editing and HuR suggest the opposite [62,63]. These studies report that $\mathrm{HuR}$, as a de-stabilizing enzyme influenced by the presence of RNA editing sites in the target RNA, nuclear-retained Cat2-transcribed nuclear RNA (Ctn RNA) [62,63]. As we did not investigate the stability of RNA in this study, we lack the evidence to refute these previous two studies. In order to investigate this point, RNA stability must be measured upon silencing of ADAR by treating the cells with actinomycin D to suppress the synthesis of mRNAs.

Over three-quarters of the RNA editing sites are found in the intronic regions. Thus, it is more likely that RNA editing affects splicing patterns. It is interesting to note that identifying RNA editing sites in spliced exons and junctions is challenging, as the sequencing reads could be mapped beyond the corresponding exon boundaries $[6,15,17,28]$. Thus, RNA editing sites near the splicing acceptor and donor sites cannot be accurately identified unless the direct comparison of RNA-seq data to the whole-genome sequencing (WGS) from the same cell is conducted, which is not ideal as the cost of WGS is much more (including computational time) than simply performing bulk RNA-seq. Thus, it is possible that the effect of RNA editing to splicing patterns is underestimated. An additional problem is that it is still a challenge to correctly identify spliced exons from short-read RNA-seq (e.g., Illumina sequencer) as $\approx 95 \%$ 
of multi-exon genes undergo alternative splicing, which results in $\approx 100,000$ alternative splicing events in major human tissues [64]. One potential solution is to use "Iso-Seq" [65-76], which allows for the capturing of transcripts over kilo nucleotides (nt) in length, recording isoforms with increased accuracy compared to shorter sequences (e.g., $<200 \mathrm{nt}$ ). However, the analysis of long reads is difficult due to the low sequence coverage, which also leads to missing of RNA editing sites to be identified. In order to understand the effects of RNA editing, a combined method of different types of RNA-seq and WGS along with bioinformatics analysis is urgently needed.

Supplementary Materials: The following are available online at http://www.mdpi.com/2571-5135/8/4/19/s1: Table S1: List of primers used in this study. Table S2: List of RBP-bound regions for 47 crosslinking-immunoprecipitation (CLIP)-seq data sets in HEK-293 cells. Table S3: Distribution of genic locations of RNA editing sites found in the RBP-bound regions. Table S4: Distribution of genic locations of RNA editing sites (in Alu elements) found in the RBP-bound regions. Table S5: Distribution of genic locations of RNA editing sites (in non-Alu elements) found in the RBP-bound regions. Table S6: Distribution of genic locations of RNA editing sites in HEK-293 cells identified with RNAEditor. Table S7: List of RNA editing islands in HEK-293 cells. Table S8: Distribution of genic locations of RNA editing islands found in the RBP-bound regions. Table S9: Numbers of RNA editing sites detected in RNA-seq data upon silencing of ADAR. The numbers of RNA editing sites are categorized on the basis of the genic regions, as shown.

Author Contributions: Conception and design: S.U.; development of methodology: T.W., G.M., and D.J.; experimentation and acquisition of data: G.M. and M.R.H.; analysis and interpretation of data: T.W., G.M., J.M.B.IV, and S.U.; original draft preparation: S.U.; review, and revision of the manuscript: all authors; project administration, funding acquisition, and supervision: J.M.B.IV and S.U.

Funding: This research was supported in part by National Institutes of Health grant R01-HL141081 (to J.B.M.) and P30 GM127607 (to S.U.); V.V. Cooke Foundation (Kentucky, U.S.A.; to S.U.); EVPRI Internal Research Grant from the Office of the Executive Vice President for Research and Innovation at the University of Louisville (to S.U.); the Deutsche Forschungsgemeinschaft (SFB834) (to S.U.); and the startup funding from the Mansbach Family, the Gheens Foundation, and other generous supporters at the University of Louisville (to S.U.).

Acknowledgments: The authors would like to thank Wenjun Jin for excellent technical assistance.

Conflicts of Interest: The authors declare no conflict of interest. The funders had no role in the design of the study; in the collection, analyses, or interpretation of data; in the writing of the manuscript, or in the decision to publish the results.

\section{References}

1. Cantara, W.A.; Crain, P.F.; Rozenski, J.; McCloskey, J.A.; Harris, K.A.; Zhang, X.; Vendeix, F.A.; Fabris, D.; Agris, P.F. The rna modification database, rnamdb: 2011 update. Nucleic Acids Res. 2011, 39, D195-D201. [CrossRef] [PubMed]

2. He, C. Grand challenge commentary: RNA epigenetics? Nat. Chem. Biol. 2010, 6, 863-865. [CrossRef] [PubMed]

3. Liu, N.; Pan, T. RNA epigenetics. Trans. Res. 2015, 165, 28-35. [CrossRef] [PubMed]

4. Roundtree, I.A.; He, C. RNA epigenetics-chemical messages for posttranscriptional gene regulation. Curr. Opin. Chem. Biol. 2016, 30, 46-51. [CrossRef]

5. Kadumuri, R.V.; Janga, S.C. Epitranscriptomic Code and Its Alterations in Human Disease. Trends Mol Med. 2018, 24, 886-903. [CrossRef]

6. Diroma, M.A.; Ciaccia, L.; Pesole, G.; Picardi, E. Elucidating the editome: Bioinformatics approaches for rna editing detection. Brief. Bioinform. 2019, 20, 436-447. [CrossRef]

7. Keegan, L.P.; Gallo, A.; O'Connell, M.A. The many roles of an rna editor. Nat. Rev. Genet. 2001, 2, 869-878. [CrossRef]

8. Hideyama, T.; Kwak, S. When does als start? Adar2-glua2 hypothesis for the etiology of sporadic als. Front. Mol. Neurosci. 2011, 4, 33. [CrossRef]

9. Savva, Y.A.; Rieder, L.E.; Reenan, R.A. The adar protein family. Genome Biol. 2012, 13, 252. [CrossRef]

10. Chen, C.X.; Cho, D.S.; Wang, Q.; Lai, F.; Carter, K.C.; Nishikura, K. A third member of the rna-specific adenosine deaminase gene family, adar3, contains both single-and double-stranded rna binding domains. RNA 2000, 6, 755-767. [CrossRef] 
11. Wang, Q.; Miyakoda, M.; Yang, W.; Khillan, J.; Stachura, D.L.; Weiss, M.J.; Nishikura, K. Stress-induced apoptosis associated with null mutation of adar1 rna editing deaminase gene. J. Biol. Chem. 2004, 279, 4952-4961. [CrossRef]

12. Higuchi, M.; Maas, S.; Single, F.N.; Hartner, J.; Rozov, A.; Burnashev, N.; Feldmeyer, D.; Sprengel, R.; Seeburg, P.H. Point mutation in an ampa receptor gene rescues lethality in mice deficient in the rna-editing enzyme adar2. Nature 2000, 406, 78-81. [CrossRef]

13. Bahn, J.H.; Lee, J.H.; Li, G.; Greer, C.; Peng, G.; Xiao, X. Accurate identification of a-to-i rna editing in human by transcriptome sequencing. Genome Res. 2012, 22, 142-150. [CrossRef] [PubMed]

14. Peng, Z.; Cheng, Y.; Tan, B.C.; Kang, L.; Tian, Z.; Zhu, Y.; Zhang, W.; Liang, Y.; Hu, X.; Tan, X.; et al. Comprehensive analysis of rna-seq data reveals extensive rna editing in a human transcriptome. Nat. Biotechnol. 2012, 30, 253-260. [CrossRef] [PubMed]

15. Ramaswami, G.; Lin, W.; Piskol, R.; Tan, M.H.; Davis, C.; Li, J.B. Accurate identification of human alu and non-alu rna editing sites. Nat. Methods 2012, 9, 579-581. [CrossRef]

16. Park, E.; Williams, B.; Wold, B.J.; Mortazavi, A. Rna editing in the human encode rna-seq data. Genome Res. 2012, 22, 1626-1633. [CrossRef]

17. Ramaswami, G.; Zhang, R.; Piskol, R.; Keegan, L.P.; Deng, P.; O'Connell, M.A.; Li, J.B. Identifying rna editing sites using rna sequencing data alone. Nat. Methods 2013, 10, 128-132. [CrossRef]

18. Solomon, O.; Oren, S.; Safran, M.; Deshet-Unger, N.; Akiva, P.; Jacob-Hirsch, J.; Cesarkas, K.; Kabesa, R.; Amariglio, N.; Unger, R.; et al. Global regulation of alternative splicing by adenosine deaminase acting on rna (adar). RNA 2013, 19, 591-604. [CrossRef]

19. Stellos, K.; Gatsiou, A.; Stamatelopoulos, K.; Perisic Matic, L.; John, D.; Lunella, F.F.; Jae, N.; Rossbach, O.; Amrhein, C.; Sigala, F.; et al. Adenosine-to-inosine rna editing controls cathepsin s expression in atherosclerosis by enabling hur-mediated post-transcriptional regulation. Nat. Med. 2016, 22, 1140-1150. [CrossRef]

20. Picardi, E.; D'Antonio, M.; Carrabino, D.; Castrignano, T.; Pesole, G. Expedit: A webserver to explore human rna editing in rna-seq experiments. Bioinform. (Oxf. Engl.) 2011, 27, 1311-1312. [CrossRef]

21. D'Antonio, M.; Picardi, E.; Castrignano, T.; D'Erchia, A.M.; Pesole, G. Exploring the rna editing potential of rna-seq data by expedit. Methods Mol. Biol. 2015, 1269, 327-338. [PubMed]

22. Zhang, Q.; Xiao, X. Genome sequence-independent identification of rna editing sites. Nat. Methods 2015, 12, 347-350. [CrossRef] [PubMed]

23. Ahn, J.; Xiao, X. Raser: Reads aligner for snps and editing sites of rna. Bioinform. (Oxf. Engl.) 2015, 31, 3906-3913. [CrossRef] [PubMed]

24. Picardi, E.; Pesole, G. Reditools: High-throughput rna editing detection made easy. Bioinform. (Oxf. Engl.) 2013, 29, 1813-1814. [CrossRef]

25. Picardi, E.; D'Erchia, A.M.; Montalvo, A.; Pesole, G. Using reditools to detect rna editing events in ngs datasets. Curr. Protoc. Bioinform. 2015, 49, 12.12.1-12.12.15. [CrossRef]

26. Kiran, A.; Baranov, P.V. Darned: A database of rna editing in humans. Bioinform. (Oxf. Engl.) 2010, 26, 1772-1776. [CrossRef]

27. Ramaswami, G.; Li, J.B. Radar: A rigorously annotated database of a-to-i rna editing. Nucleic Acids Res. 2014, 42, D109-D113. Available online: http://rnaedit.com/download/ (accessed on 4 September 2017). [CrossRef]

28. Weirick, T.; Militello, G.; Ponomareva, Y.; John, D.; Doring, C.; Dimmeler, S.; Uchida, S. Logic programming to infer complex rna expression patterns from rna-seq data. Brief. Bioinform. 2016, 19, 199-209. [CrossRef]

29. Brinegar, A.E.; Cooper, T.A. Roles for rna-binding proteins in development and disease. Brain Res. 2016, 1647, 1-8. [CrossRef]

30. Calabretta, S.; Richard, S. Emerging roles of disordered sequences in rna-binding proteins. Trends. Biochem. Sci. 2015, 40, 662-672. [CrossRef]

31. Cookson, M.R. Rna-binding proteins implicated in neurodegenerative diseases. Wiley Interdiscip. Rev. RNA 2017, 8, e1397. [CrossRef] [PubMed]

32. Dash, S.; Siddam, A.D.; Barnum, C.E.; Janga, S.C.; Lachke, S.A. Rna-binding proteins in eye development and disease: Implication of conserved rna granule components. Wiley Interdiscip. Rev. RNA 2016, 7, 527-557. [CrossRef] [PubMed]

33. de Bruin, R.G.; Rabelink, T.J.; van Zonneveld, A.J.; van der Veer, E.P. Emerging roles for rna-binding proteins as effectors and regulators of cardiovascular disease. Eur. Heart J. 2016, 38, 1380-1388. [CrossRef] [PubMed] 
34. Fredericks, A.M.; Cygan, K.J.; Brown, B.A.; Fairbrother, W.G. Rna-binding proteins: Splicing factors and disease. Biomolecules 2015, 5, 893-909. [CrossRef]

35. Sephton, C.F.; Yu, G. The function of rna-binding proteins at the synapse: Implications for neurodegeneration. Cell. Mol. Life Sci. 2015, 72, 3621-3635. [CrossRef]

36. Zhao, J.; Ohsumi, T.K.; Kung, J.T.; Ogawa, Y.; Grau, D.J.; Sarma, K.; Song, J.J.; Kingston, R.E.; Borowsky, M.; Lee, J.T. Genome-wide identification of polycomb-associated rnas by rip-seq. Mol. Cell 2010, 40, 939-953. [CrossRef]

37. Wessels, H.H.; Hirsekorn, A.; Ohler, U.; Mukherjee, N. Identifying rbp targets with rip-seq. Methods Mol. Biol. (Clifton N. J.) 2016, 1358, 141-152.

38. Ule, J.; Jensen, K.B.; Ruggiu, M.; Mele, A.; Ule, A.; Darnell, R.B. Clip identifies nova-regulated rna networks in the brain. Science 2003, 302, 1212-1215. [CrossRef]

39. Hafner, M.; Landthaler, M.; Burger, L.; Khorshid, M.; Hausser, J.; Berninger, P.; Rothballer, A.; Ascano, M., Jr.; Jungkamp, A.C.; Munschauer, M.; et al. Transcriptome-wide identification of rna-binding protein and microrna target sites by par-clip. Cell 2010, 141, 129-141. [CrossRef]

40. Konig, J.; Zarnack, K.; Rot, G.; Curk, T.; Kayikci, M.; Zupan, B.; Turner, D.J.; Luscombe, N.M.; Ule, J. Iclip reveals the function of hnrnp particles in splicing at individual nucleotide resolution. Nat. Struct. Mol. Biol. 2010, 17, 909-915. [CrossRef]

41. Wang, Z.; Kayikci, M.; Briese, M.; Zarnack, K.; Luscombe, N.M.; Rot, G.; Zupan, B.; Curk, T.; Ule, J. Iclip predicts the dual splicing effects of tia-rna interactions. PLoS Biol. 2010, 8, e1000530. [CrossRef] [PubMed]

42. Yang, Y.C.; Di, C.; Hu, B.; Zhou, M.; Liu, Y.; Song, N.; Li, Y.; Umetsu, J.; Lu, Z.J. Clipdb: A clip-seq database for protein-rna interactions. BMC Genom. 2015, 16, 51. [CrossRef] [PubMed]

43. Guo, Z.W.; Xie, C.; Yang, J.R.; Li, J.H.; Yang, J.H.; Zheng, L. Mtibase: A database for decoding microrna target sites located within cds and 5'utr regions from clip-seq and expression profile datasets. Database J. Biol. Databases Curation 2015. [CrossRef]

44. Hu, B.; Yang, Y.T.; Huang, Y.; Zhu, Y.; Lu, Z.J. Postar: A platform for exploring post-transcriptional regulation coordinated by rna-binding proteins. Nucleic Acids Res. 2017, 45, D104-D114. [CrossRef] [PubMed]

45. Li, J.H.; Liu, S.; Zhou, H.; Qu, L.H.; Yang, J.H. Starbase v2.0: Decoding mirna-cerna, mirna-ncrna and protein-rna interaction networks from large-scale clip-seq data. Nucleic Acids Res. 2014, 42, D92-D97. [CrossRef]

46. Yang, J.H.; Li, J.H.; Shao, P.; Zhou, H.; Chen, Y.Q.; Qu, L.H. Starbase: A database for exploring microrna-mrna interaction maps from argonaute clip-seq and degradome-seq data. Nucleic Acids Res. 2011, 39, D202-D209. Available online: http://starbase.sysu.edu.cn/download.php (accessed on 4 September 2017). [CrossRef]

47. Gaisler-Salomon, I.; Kravitz, E.; Feiler, Y.; Safran, M.; Biegon, A.; Amariglio, N.; Rechavi, G. Hippocampus-specific deficiency in rna editing of glua2 in alzheimer's disease. Neurobiol. Aging 2014, 35, 1785-1791. [CrossRef]

48. Xiang, J.F.; Yin, Q.F.; Chen, T.; Zhang, Y.; Zhang, X.O.; Wu, Z.; Zhang, S.; Wang, H.B.; Ge, J.; Lu, X.; et al. Human colorectal cancer-specific ccat1-1 lncrna regulates long-range chromatin interactions at the myc locus. Cell Res. 2014, 24, 513-531. [CrossRef]

49. Yamashita, T.; Kwak, S. The molecular link between inefficient glua2 q/r site-rna editing and tdp-43 pathology in motor neurons of sporadic amyotrophic lateral sclerosis patients. Brain Res. 2014, 1584, 28-38. [CrossRef]

50. Wang, Q.; Hui, H.; Guo, Z.; Zhang, W.; Hu, Y.; He, T.; Tai, Y.; Peng, P.; Wang, L. Adar1 regulates arhgap26 gene expression through rna editing by disrupting mir-30b-3p and mir-573 binding. RNA 2013, 19, 1525-1536. [CrossRef]

51. Quinlan, A.R.; Hall, I.M. Bedtools: A flexible suite of utilities for comparing genomic features. Bioinform. (Oxf. Engl.) 2010, 26, 841-842. [CrossRef] [PubMed]

52. Militello, G.; Weirick, T.; John, D.; Doring, C.; Dimmeler, S.; Uchida, S. Screening and validation of lncrnas and circrnas as mirna sponges. Brief. Bioinform. 2016, 18, 780-788. [CrossRef] [PubMed]

53. John, D.; Weirick, T.; Dimmeler, S.; Uchida, S. Rnaeditor: Easy detection of rna editing events and the introduction of editing islands. Brief. Bioinform. 2016, 18, 993-1001. [CrossRef] [PubMed]

54. Chang, K.Y.; Ramos, A. The double-stranded rna-binding motif, a versatile macromolecular docking platform. FEBS J. 2005, 272, 2109-2117. [CrossRef] [PubMed]

55. Chen, Y.; Varani, G. Protein families and rna recognition. FEBS J. 2005, 272, 2088-2097. [CrossRef] [PubMed]

56. Masliah, G.; Barraud, P.; Allain, F.H. Rna recognition by double-stranded rna binding domains: A matter of shape and sequence. Cell. Mol. Life Sci. 2013, 70, 1875-1895. [CrossRef] [PubMed]

57. Stefl, R.; Skrisovska, L.; Allain, F.H. Rna sequence- and shape-dependent recognition by proteins in the ribonucleoprotein particle. EMBO Rep. 2005, 6, 33-38. [CrossRef] 
58. Wang, I.X.; So, E.; Devlin, J.L.; Zhao, Y.; Wu, M.; Cheung, V.G. Adar regulates rna editing, transcript stability, and gene expression. Cell Rep. 2013, 5, 849-860. [CrossRef]

59. Peng, S.S.; Chen, C.Y.; Xu, N.; Shyu, A.B. Rna stabilization by the au-rich element binding protein, hur, an elav protein. EMBO J. 1998, 17, 3461-3470. [CrossRef]

60. Fan, X.C.; Steitz, J.A. Overexpression of hur, a nuclear-cytoplasmic shuttling protein, increases the in vivo stability of are-containing mrnas. EMBO J. 1998, 17, 3448-3460. [CrossRef]

61. Levy, N.S.; Chung, S.; Furneaux, H.; Levy, A.P. Hypoxic stabilization of vascular endothelial growth factor mrna by the rna-binding protein hur. J. Biol. Chem. 1998, 273, 6417-6423. [CrossRef] [PubMed]

62. Anantharaman, A.; Tripathi, V.; Khan, A.; Yoon, J.H.; Singh, D.K.; Gholamalamdari, O.; Guang, S.; Ohlson, J.; Wahlstedt, H.; Ohman, M.; et al. Adar2 regulates rna stability by modifying access of decay-promoting rna-binding proteins. Nucleic Acids Res. 2017, 45, 4189-4201. [CrossRef] [PubMed]

63. Anantharaman, A.; Gholamalamdari, O.; Khan, A.; Yoon, J.H.; Jantsch, M.F.; Hartner, J.C.; Gorospe, M.; Prasanth, S.G.; Prasanth, K.V. Rna-editing enzymes adar1 and adar2 coordinately regulate the editing and expression of ctn rna. FEBS Lett. 2017, 591, 2890-2904. [CrossRef] [PubMed]

64. Pan, Q.; Shai, O.; Lee, L.J.; Frey, B.J.; Blencowe, B.J. Deep surveying of alternative splicing complexity in the human transcriptome by high-throughput sequencing. Nat. Genet. 2008, 40, 1413-1415. [CrossRef]

65. Abdel-Ghany, S.E.; Hamilton, M.; Jacobi, J.L.; Ngam, P.; Devitt, N.; Schilkey, F.; Ben-Hur, A.; Reddy, A.S. A survey of the sorghum transcriptome using single-molecule long reads. Nat. Commun. 2016, 7, 11706. [CrossRef]

66. Cartolano, M.; Huettel, B.; Hartwig, B.; Reinhardt, R.; Schneeberger, K. Cdna library enrichment of full length transcripts for smrt long read sequencing. PLoS ONE 2016, 11, e0157779. [CrossRef]

67. Gonzalez-Ibeas, D.; Martinez-Garcia, P.J.; Famula, R.A.; Delfino-Mix, A.; Stevens, K.A.; Loopstra, C.A.; Langley, C.H.; Neale, D.B.; Wegrzyn, J.L. Assessing the gene content of the megagenome: Sugar pine (pinus lambertiana). G3 (Bethesda Md.) 2016, 6, 3787-3802. [CrossRef]

68. Hoang, N.V.; Furtado, A.; Mason, P.J.; Marquardt, A.; Kasirajan, L.; Thirugnanasambandam, P.P.; Botha, F.C.; Henry, R.J. A survey of the complex transcriptome from the highly polyploid sugarcane genome using full-length isoform sequencing and de novo assembly from short read sequencing. BMC Genom. 2017, 18, 395. [CrossRef]

69. Jiang, X.; Hall, A.B.; Biedler, J.K.; Tu, Z. Single molecule rna sequencing uncovers trans-splicing and improves annotations in anopheles stephensi. Insect Mol. Biol. 2017, 26, 298-307. [CrossRef]

70. Kim, M.A.; Rhee, J.S.; Kim, T.H.; Lee, J.S.; Choi, A.Y.; Choi, B.S.; Choi, I.Y.; Sohn, Y.C. Alternative splicing profile and sex-preferential gene expression in the female and male pacific abalone haliotis discus hannai. Genes 2017, 8, 99. [CrossRef]

71. Kuo, R.I.; Tseng, E.; Eory, L.; Paton, I.R.; Archibald, A.L.; Burt, D.W. Normalized long read rna sequencing in chicken reveals transcriptome complexity similar to human. BMC Genom. 2017, 18, 323. [CrossRef] [PubMed]

72. Liu, X.; Mei, W.; Soltis, P.S.; Soltis, D.E.; Barbazuk, W.B. Detecting alternatively spliced transcript isoforms from single-molecule long-read sequences without a reference genome. Mol. Ecol. Resour. 2017, 7, 1243-1256. [CrossRef] [PubMed]

73. O'Grady, T.; Wang, X.; Honer Zu Bentrup, K.; Baddoo, M.; Concha, M.; Flemington, E.K. Global transcript structure resolution of high gene density genomes through multi-platform data integration. Nucleic Acids Res. 2016, 44, e145. [CrossRef] [PubMed]

74. Singh, N.; Sahu, D.K.; Chowdhry, R.; Mishra, A.; Goel, M.M.; Faheem, M.; Srivastava, C.; Ojha, B.K.; Gupta, D.K.; Kant, R. Isoseq analysis and functional annotation of the infratentorial ependymoma tumor tissue on pacbio rsii platform. Meta Gene 2016, 7, 70-75. [CrossRef] [PubMed]

75. Tombacz, D.; Balazs, Z.; Csabai, Z.; Moldovan, N.; Szucs, A.; Sharon, D.; Snyder, M.; Boldogkoi, Z. Characterization of the dynamic transcriptome of a herpesvirus with long-read single molecule real-time sequencing. Sci. Rep. 2017, 7, 43751. [CrossRef] [PubMed]

76. Zulkapli, M.M.; Rosli, M.A.F.; Salleh, F.I.M.; Mohd Noor, N.; Aizat, W.M.; Goh, H.H. Iso-seq analysis of nepenthes ampullaria, nepenthes rafflesiana and nepenthes $\mathrm{x}$ hookeriana for hybridisation study in pitcher plants. Genom. Data 2017, 12, 130-131. [CrossRef] [PubMed]

(C) 2019 by the authors. Licensee MDPI, Basel, Switzerland. This article is an open access article distributed under the terms and conditions of the Creative Commons Attribution (CC BY) license (http://creativecommons.org/licenses/by/4.0/). 